\title{
HERMANOSY HERMANAS EN CONTIENDA EN LAS COMEDIAS CÓMICAS DE CALDERÓN (CON UNA MIRADA HACIA LOPE)
}

Fausta Antonucci

Università degli Studi Roma Tre Dipartimento di Lingue, Letterature e Culture straniere Via del valco di san Paolo, 19 00146, Roma Italia fausta.antonucci@uniroma3.it

\section{Panorama crítico}

En una nota a su importante perfil histórico-crítico del teatro del siglo XVII, apuntaba Marc Vitse que, en la producción dramática del segundo cuarto del siglo, se observa "el desarrollo importante, como tema argumental, de la competencia entre hermanos que ya asomaba en las parejas de hermanas de Tirso»" ${ }^{1}$ A continuación, listaba una serie de títulos de Calderón que tratan el tema «en registros muy diversos», desde el francamente trágico (Los cabellos de Absalón) al francamente cómico (Con quien vengo, vengo, No hay burlas con el amor, Guárdate del agua mansa), pasando por una gama intermedia de matices genéricos (En la vida todo es verdad y todo mentira, La banda y la flor, De una causa dos efectos, Auristela $y$ Lisidante); un corpus que puede ampliarse con piezas no mencionadas

\footnotetext{
${ }^{1}$ Vitse, 1983, p. 582, n. 100.
} 
porVitse como La dama duende, Mujer, llora y vencerás o La selva confusa ${ }^{2}$. Mi propósito en estas páginas es el de estudiar las comedias de este corpus cuyo registro cómico es indudable y ampliamente aceptado por la crítica: La dama duende, en la que el tema de la competencia amorosa entre hermanos constituye uno de los resortes de la intriga; Con quien vengo, vengo, No hay burlas con el amor, Guárdate del agua mansa, que giran en cambio alrededor de un conflicto de caracteres y comportamientos entre hermanas. Se trata de un conjunto marcado por la coherencia genérica (todas son comedias de capa y espada, de ambientación urbana contemporánea) y por el escalonamiento cronológico, pues las piezas que lo componen se distribuyen en un lapso que va desde 1629 ( $\mathrm{La}$ dama duende) a 1642-1644 (fecha propuesta por Arellano y García Ruiz para El agua mansa, primera versión de Guárdate del agua mansa y de la que me ocuparé en este estudio) $)^{3}$. Esto permite observar eventuales cambios en el tratamiento del tema dramático del conflicto fraterno. Un conflicto que, dado el carácter cómico de las piezas que estudio, se supone que no deberá ser demasiado áspero, con sufrimientos o consecuencias importantes y permanentes para los personajes involucrados. Ya Arellano, en un fundamental artículo de 1994, señalaba la convencionalidad cómica del esquema formado por dos hermanas o primas (como en ¿Cuál es mayor perfección, hermosura o discreción?) de carácter opuesto, que se combina a menudo con otro esquema binario tópico, el de la pareja formada por la melindrosa y el galán «al uso» que rehuyen del amor y terminan enamorándose (combinación que se da en No hay burlas con el amor $)^{4}$.

Ahora bien, una pregunta a la que creo que es importante contestar, siempre teniendo en cuenta el carácter cómico de las piezas analizadas, es cómo puede interpretarse el tema de la rivalidad fraterna en el contexto de un sistema de personajes que reproduce, como en toda la Comedia Nueva, y para volver a emplear palabras deVitse, «una conste-

${ }^{2}$ Y otras más que menciona y analiza Suárez Miramón, en prensa.

${ }^{3}$ Arellano y García Ruiz, 1989, p. 59. La fecha de 1630 propuesta por Osma, 1928 para Con quien vengo, vengo es generalmente aceptada por la crítica; sobre la fecha de 1635 para No hay burlas con el amor ver Arellano, 1981, pp. 141-143. La fecha de 1629 para La dama duende es un dato reconocido que se deduce de la mención de los festejos madrileños por el bautizo del príncipe Baltasar Carlos que se encuentra en los primeros versos de la comedia.

${ }^{4}$ Arellano, 1994, pp. 115-119. 
lación familiar» ${ }^{5}$. Si atendemos a la propuesta de interpretación de Vitse (muy tentativa, como él mismo admite) ${ }^{6}$, en la comedia del segundo cuarto del siglo XVII se observa una serie de cambios en las relaciones que mueven esta constelación. El más importante sería una suerte de «colaboración» entre padres e hijos en el mantenimiento del honor familiar, y la reducción o desaparición de la burla y la degradación a la que se somete la figura paterna en la comedia de la época anterior ${ }^{7}$. Para comprobar si las comedias que analizamos se corresponden con este modelo, habremos de estudiar su configuración dramática, pero también será muy útil esbozar alguna comparación con comedias de la fase anterior que dramatizan el mismo tema. Como apuntabaVitse en la cita inicial, en las intrigas de Tirso asoman a menudo parejas conflictivas de hermanas ${ }^{8}$; pero al parecer fue Lope quien introdujo por primera vez el tema de la rivalidad fraterna en la comedia, con El amigo hasta la muerte (1610-1612) y La dama boba (1613) ${ }^{9}$. Aunque algunos críticos ya han mencionado los parecidos entre esta última y No hay burlas con el amor ${ }^{10}$, y su papel de "primera obra genial» en el tratamiento del «antagonismo entre la dama bella y la discreta ${ }^{11}$, creo que es posible extraer más jugo de la comparación, así como de los parecidos y diferencias — nunca

${ }^{5}$ Vitse, 1983, pp. 513-514 y ss.

${ }^{6}$ «Recordemos que no indicaremos a continuación sino algunos rasgos distintivos con relación a la producción anterior. Es evidente, por ejemplo, que no desaparecen las oposiciones entre personajes paternos y personajes filiales: lo que ocurre es que pasan, dramáticamente, a plano muy secundario [...]. Tenemos por otra parte clara conciencia del estado extremadamente fragmentario e insuficiente del estudio del teatro cómico de esta segunda fase: las orientaciones generales que proponemos tendrán pues carácter aún más hipotético que lo hasta ahora expuesto» (Vitse, 1983, pp. 576-577, n. 96).

${ }^{7}$ Vitse, 1983, pp. 576-581.

${ }^{8}$ Un dato recordado asimismo por Couderc, 2006, pp. 202-203, con más referencias críticas y una útil lista de títulos.

${ }^{9}$ Es lo que he podido deducir de una atenta búsqueda en la BD Artelope (http://artelope.uv.es/): en la producción más temprana de Lope, aunque existen intrigas protagonizadas por parejas de hermanos o hermanas, no se percibe la conflictividad que asoma, por primera vez, en las comedias mencionadas. Las piezas de Tirso en las que aparecen parejas conflictivas de hermanas son, en todo caso, muy próximas como datación, teniendo en cuenta que la cronología tirsiana es aún más hipotética que la de Lope.

${ }^{10}$ Josa, 2002, p. 248.

${ }^{11}$ Roncero, 2016 (artículo que estudia un corpus formado por No hay burlas con el amor, El agua mansa y ¿Cuál es mayor perfección, hermosura o discreción? centrándose en el antagonismo entre dama discreta y dama hermosa como motivo cómico, más que en el conflicto fraterno). 
observados por nadie, que yo sepa - entre El amigo hasta la muerte y La dama duende.

\section{LA DAMA DUENDE Y LA RIVALIDAD ENTRE HERMANOS}

La intriga de La dama duende es tan conocida que creo poder ahorrarme un resumen demasiado detallado. Baste recordar aquí que un caballero forastero, don Manuel, es alojado con su criado en casa de un amigo madrileño, don Juan de Toledo. En la casa viven también dos hermanos de este: don Luis, enamorado de doña Beatriz, la misma dama a la que quiere su hermano mayor, y doña Ángela, joven viuda que su estado obliga a vivir recatada. Con la ayuda de su criada, doña Ángela descubre cómo dejar billetes y regalos en el cuarto del huésped, y la correspondencia alimenta una relación a distancia llena de misterio y riesgos, porque don Manuel no entiende cómo puede entrar a su cuarto la «dama duende», y doña Ángela se expone continuamente al riesgo de ser descubierta, por él o por sus hermanos, mientras mueve la alacena que cierra la puerta del cuarto del huésped que da al resto de la casa. Aunque al final la treta se descubre, con los consabidos duelos y amenazas de muerte a la hermana traidora, el desenlace es feliz, con una doble boda, la de don Manuel y doña Ángela y la de don Juan y doña Beatriz.

El carácter canónico de La dama duende, así como la centralidad en la intriga de las tensiones entre hermanos, han determinado una peculiar insistencia crítica en las relaciones fraternas, que han sido a menudo muy mal interpretadas. Si por un lado se ha visto en doña Ángela una víctima de sus hermanos, que va buscando su libertad femenina por encima de todo, incluso del amor, por otro se ha interpretado el personaje de don Luis como un emblema de negatividad. Para argumentar esta lectura se ha aducido, ahora su preocupación obsesiva por el honor familiar, que delataría una atención casi incestuosa por su hermana; ahora sus celos y envidia hacia don Juan por el amor de Beatriz ${ }^{12}$. No voy a repetir aquí las argumentaciones contrarias, extremadamente convincentes, que expuso Arellano en un trabajo de 2001, ni las mías propias en el prólogo a mi edición de 2005 de La dama duende (de la que cito el texto). No hay duda para mí de que las tensiones fraternas en $\mathrm{La}$

${ }^{12}$ Un repaso de la crítica en Feijoo, 1998 y Antonucci, 1999; más informaciones en Pérez Magallón, 2011. 
dama duende se presentan bajo una luz cómica: lo cual no quiere decir, por otra parte, que en los pequeños incidentes de la vida familiar que Calderón nos muestra no pueda leerse un guiño del dramaturgo a las causas reales de tensión que anidan en una casa en la que un mayorazgo decide por los hermanos menores, y estos convienen en que «sufrirle es mejor: / que es nuestro hermano mayor / y comemos de alimentos» (vv. 534-536) ${ }^{13}$. Así como suena vívida y verosímil la resignación de don Juan cuando observa, medio en broma medio en serio, que no cree que el huésped le dé ningún problema a su hermana, «sino que tú y don Luis mostráis disgusto / por ser cosa en que yo he tenido gusto» (vv. 1869-1870). Pero estas alusiones a las situaciones tensas que pueden darse efectivamente entre hermanos no pasan, en mi opinión, de toques que podríamos calificar de costumbristas, al estilo de las alusiones a las fiestas para el bautizo de Baltasar Carlos o a las fuentes de Madrid que menciona Cosme, el criado de don Manuel. Quiero decir que, si por un lado remiten a sentimientos y desavenencias que el auditorio puede fácilmente compartir, pues caben en la experiencia de todos, no debe atribuírseles una trascendencia que no tienen, interpretándolos como indicios de un tratamiento serio y hasta potencialmente trágico del tema. Algo parecido puede afirmarse de observaciones sembradas aquí y allá en las demás comedias de nuestro corpus, como la de que "si hay envidia entre hermanos, / es la más cruel envidia» (vv. 1396-1397) que se encuentra en No hay burlas con el amor; o la exclamación de Clara en El agua mansa cuando planea vengarse de su hermana Eugenia: ${ }_{i} \mathrm{Oh}$, envidia, oh, envidia, cuánto / daño has hecho a las mujeres!» (vv. 18191820).

Cuando tratemos estas dos piezas, veremos que estas consideraciones no son el preludio de situaciones serias y trascendentes, sino, muy al contrario, de unas trazas ingeniosas destinadas a complicar aún más el enredo y por lo mismo a divertir al auditorio. Dicho de otra forma, la envidia entre hermanos o hermanas, aunque sin duda es un dato real y como a tal se alude a ello, no es en estas comedias sino uno de los resortes de la intriga. El caso de La dama duende nos lo muestra con toda claridad. Sin los celos que don Luis experimenta por su hermano y Beatriz, no se explicaría su escucha al paño, en la segunda jornada, de los proyectos de doña Ángela acerca del encuentro nocturno con el

${ }^{13}$ Sobre la relación de don Juan con sus hermanos, puede verse también Greer, 1994, p. 90. 
huésped, que determinan en la tercera jornada su irrupción en el cuarto de la hermana y a continuación el descubrimiento de la alacena y del pasaje al cuarto de don Manuel. Más en general, la competencia de don Luis con su hermano es uno de los resortes en que se basa la larga serie de secuencias paralelísticas que vertebran la comedia. Baste pensar en la correspondencia puntual entre las visitas al cuarto de Ángela de don Juan y las de don Luis, que ocupan porciones importantes de la segunda y de la tercera jornad $a^{14}$.

Pero las implicaciones de la relación entre don Juan y don Luis no tienen que ver solo con la construcción de la intriga (o forma del contenido, si quisiéramos adoptar la útil terminología de Hjelmslev), sino también con la construcción del significado de la comedia (o sustancia del contenido). Recordemos a este respecto que la rivalidad que opone a don Luis y a don Juan no se realiza solo en el plano amoroso, sino también en el plano del mantenimiento del honor familiar. A la pregunta maliciosa de su criado Rodrigo, que al final del primer cuadro de la comedia sospecha que el mayor motivo del disgusto de don Luis sean «los celos / de tu hermano y Beatriz bella» (vv. 315-316), el caballero contesta que no, que el disgusto peor «es que sea / mi hermano tan poco atento / que llevar a casa quiera / un hombre mozo, teniendo, / Rodrigo, una hermana en ella / viuda y moza» (vv. 320-325).

Ha llegado el momento de utilizar como herramienta de análisis la sugerencia de MarcVitse que recordaba al comienzo, es decir, la oportunidad de estudiar el sistema de personajes de la Comedia Nueva como una constelación familiar, en la que el rol paterno no necesariamente coincide con la figura del padre. Examinando a los dos hermanos de $\mathrm{La}$ dama duende bajo este prisma, se ve muy claramente que don Juan desempeña al mismo tiempo el papel de galán — para con Beatriz-y el de padre — para con doña Ángela—; y que don Luis quisiera suplantar a su hermano en ambos papeles. Como a menudo sucede en la realidad, estas fantasías de suplantación están destinadas al fracaso. En lo que al papel de galán se refiere, desde el primer cuadro de la comedia queda muy claro que Beatriz no quiere a don Luis. En cuanto al rol paterno, hay que reconocer que, si don Luis fracasa, tampoco don Juan consigue desempeñarlo satisfactoriamente. De hecho Ángela, en relación con ambos hermanos, actúa exactamente como tantas hijas que, en la comedia del primer cuarto del siglo, se burlan de las prevenciones del padre para

${ }^{14}$ Para un análisis detallado de la construcción de la comedia, ver Antonucci, 2000. 
lograr su objetivo: utiliza, para pasar al cuarto de don Manuel, la misma alacena que don Juan había colocado para evitar que el huésped pudiera comunicarse con el resto de la casa; se las ingenia para mantener una relación amorosa en su misma casa, ya que no puede salir sino tapada y a costa de grandes riesgos.Y cuando, en el desenlace, don Juan la encierra en el cuarto del huésped - que cree vacío- tras haberla encontrado mientras huía de noche a refugiarse en casa de Beatriz, obtiene un efecto completamente contrario al esperado, pues en vez de incomunicarla la reúne con don Manuel.

Ahora bien, las dinámicas familiares que acabo de resumir creo que pueden leerse como una actualización más del tema de la victoria de los hijos sobre los recelos y los miedos de la instancia paterna, tema que según Vitse caracteriza la comedia del primer cuarto del siglo. A este respecto, la anunciada comparación con El amigo hasta la muerte de Lope nos permite comprobar dos cosas: por un lado, la homología sustancial del tema cómico de la victoria de los hijos sobre los padres en ambas comedias; por otro, gracias al peculiar estatuto genérico de El amigo hasta la muerte, la comicidad sin sombras que caracteriza en La dama duende tanto esta victoria como, paralelamente, las dinámicas de rivalidad y celos que oponen a los dos hermanos.

Publicada en la Parte XI (1618), y compuesta probablemente entre 1610 y $1612^{15}$, El amigo hasta la muerte es una pieza híbrida, mayoritariamente una comedia urbana, pero con rasgos de comedia de cautivos y hasta, en el final, de drama, con muertes e intervención de personajes históricos como Felipe II y el duque de Medina Sidonia ${ }^{16}$. La intriga queda a mil leguas de la estructura «matemática» y coherente de La dama duende: el tema central es el de los dos amigos dispuestos a renunciar al amor y hasta a la vida en nombre de su amistad; como corolario, hay un padre anciano que quiere casar a su hija Ángela con un Otavio, hombre avaro y ya entrado en años, y que tiene dos hijos más: uno, Federico, trabajador y prudente, otro, Bernardo, que gasta alegremente su dinero y su tiempo con gran preocupación del padre. Federico y Bernardo rivalizan en el amor por Julia; Ángela es amiga de Julia y enamorada de su hermano don Sancho, con el que acabará casándose en el desenlace. A su vez, Bernardo, gran amigo de don Sancho, se casará en el final con

${ }^{15}$ Este lapso es el que proponen Morley y Bruerton (1940). Trambaioli, 2014 propone adelantar la datación con argumentos que no me llegan a convencer.

${ }^{16}$ Antonucci, 2011; Badía Herrera, 2012, p. 3. 
Julia. Más allá de las diferencias y de la sobreabundancia de motivos dramáticos que caracteriza El amigo hasta la muerte, reconocemos con facilidad el mismo esquema pentagonal de personajes que vertebra $\mathrm{La}$ dama duende $e^{17}$ : dos parejas de galán y dama unidas por el amor recíproco, mientras que la función del galán destinado a quedar excluido del desenlace matrimonial se duplica en dos personajes, Federico y Otavio; la función paterna, que en La dama duende era asumida por uno de los galanes, la desempeña aquí el padre de Ángela, Federico y Bernardo. Mientras Otavio no tiene correspondencia en el sistema de personajes de La dama duende, Federico recuerda en muchos aspectos a don Luis: no solo porque está enamorado de la dama de su hermano, sino porque, en al menos tres situaciones, su obstinado galanteo se manifiesta en formas que me parece que encuentran cierto eco en situaciones análogas de $\mathrm{La}$ dama duende. En la escena inicial persigue a Julia, tapada, impidiéndole el paso hasta que la dama tiene que descubrirse; cuando averigua quién es, no por ello ceja en su persecución, aunque sabe que es la enamorada de su hermano Bernardo (vv. 1-94); situaciones que recuerdan tanto la persecución de doña Ángela tapada por don Luis, como los requiebros de este a Beatriz después del duelo, en el primer cuadro de la primera jornada. En el tercer acto, Federico suplica a su hermana Ángela que interceda por él con Julia que ha ido a visitarla, insistiendo a pesar de su negativa (vv. 2550-2609); lo que recuerda una escena análoga de la segunda jornada de La dama duende, en la que Luis suplica a Ángela que detenga a Beatriz. Finalmente, Federico no renuncia a ir por la noche debajo del balcón de Julia, aun sabiendo perfectamente que ella no lo quiere (vv. 2747-2758); lo que podría recordar la irrupción nocturna de don Luis en el cuarto de su hermana en busca de Beatriz, a la que cree encontrar en coloquio amoroso con don Juan. La conclusión de esta tríada de situaciones es, en El amigo hasta la muerte, trágica ${ }^{18}$ : debajo del balcón están también Bernardo y don Sancho, quienes, sin reconocer que se trata de Federico, le intiman irse; el enfrentamiento degenera en un duelo en el que don Sancho mata a Federico. Bernardo, que quiere salvarle la vida a su amigo, se autodenuncia como culpable de la muerte

\footnotetext{
${ }^{17}$ Para una definición del esquema pentagonal, herramienta ya utilizada por críticos como Serralta y Profeti entre otros, ver Couderc, 2006, pp. 71-78.

${ }^{18}$ Una conclusión que ya se presagiaba desde el comienzo, cuando Federico, ante el rechazo de Julia, afirma «he topado / mi muerte» (vv. 134-135) pero no atiende al consejo del criado: «Huir con cuidado, / pues conoces que es tu muerte» (vv. 135-136).
} 
de su hermano, con lo cual sume a su padre en un sufrimiento doble: por la pérdida de un hijo y por la perspectiva de perder al otro hijo en el cadalso por fratricida. Aunque el desenlace es feliz, pues el mismísimo rey Felipe II otorga su perdón a Bernardo y Sancho, es evidente que la exclusión del hermano rival de la formación final de las parejas no se realiza en formas puramente cómicas. La sombra proyectada por su muerte y por el encarcelamiento de los dos amigos afecta asimismo, al menos en parte, la victoria de los deseos amorosos de las dos parejas sobre los proyectos paternos; y esto a pesar de que, por un largo tramo de la intriga, prevalece un tratamiento cómico de esta pugna familiar, centrado en la indecisión de Otavio entre Ángela y Julia, los equívocos que crea y el fastidio que genera en ambos padres.

Que se comparta o no mi propuesta de ver algunos parecidos entre la actuación de Federico y la del don Luis de La dama duende, creo que es indudable la diferencia en el tratamiento del tema de los hermanos rivales que hace Lope en El amigo hasta la muerte. Una diferencia que permite apreciar — por contraste — la comicidad depurada de las dinámicas familiares de La dama duende y su construcción equilibrada y perfecta.

\section{HeRMANAS EN CONTIENDA}

Después de La dama duende no volvemos a encontrar en las comedias de capa y espada calderonianas el tema de los dos hermanos en competencia amorosa por la misma mujer. Al contrario, en este subgénero cómico Calderón explota, a partir de 1630, el tema de las dos hermanas de carácter e inclinaciones diferentes, cuya primera aparición se da en Con quien vengo, vengo, declinándose luego con una mayor acentuación de la contienda fraterna en No hay burlas con el amor y El agua mansa. Trazaré aquí muy someramente las principales dinámicas de intriga de estas tres comedias, en lo que tienen de análogo, para luego profundizar en aspectos distintos de cada uno de los textos. El resorte básico es, en todas, la presencia de una pareja de hermanas de inclinación muy diferente: enamorada la menor de un galán, que curiosamente se llama don Juan en las tres comedias, mientras que la mayor rehúye del amor y controla por lo mismo a la hermana para evitar que cometa deslices que puedan dañar el honor familiar. La dama que se niega al amor, según un esquema ya muy practicado en el teatro cómico del primer cuarto del siglo, termina enamorándose pero, en cómico contrappasso a su resisten- 
cia inicial, de un galán que no le conviene o al que no puede pretender porque cree que es el enamorado de su hermana. Al final estas dificultades se superan, de un modo u otro, pero quedan burladas y frustradas por completo las pretensiones a desempeñar un rol paterno hacia su hermana menor; la lógica cómica la reconduce a su papel de hija, y por tanto de mujer enamorada. En las tres comedias encontramos asimismo un personaje que desempeña el rol de guardián del honor: hermano, en Con quien vengo, vengo, padre en No hay burlas con el amor y El agua mansa. Como es esperable en unas comedias cómicas, su vigilancia se ve continuamente eludida y burlada, y hasta deben consentir, en el caso de No hay burlas con el amor y El agua mansa, a unos enlaces matrimoniales distintos de los que habían planeado para sus hijas.

Con quien vengo, vengo se abre con una disputa entre las dos hermanas por un billete que Leonor, la menor, ha escrito a su amado don Juan para citarle de noche en el jardín de su casa. Cuando Lisarda, la mayor, logra leer el papel no reacciona sin embargo de forma agresiva; al contrario, se ofrece a acompañar a Leonor a la cita, disfrazada de criada, para vigilar sobre su conducta y, al mismo tiempo, evitarle la humillación y el riesgo de tener que depender de la discreción de una criada. Lisarda se nos muestra pues desde la primera escena como una guardiana del honor llena de sensatez y de buen criterio: no amenaza con denunciar a Leonor al hermano sino que elige ser su cómplice para salvaguardia de su «opinión». Esto marca pues una diferencia muy sensible con el personaje de Beatriz en No hay burlas con el amor, que reacciona de forma escandalizada y excesiva, incluso a nivel lingüístico, al descubrimiento de los amores de su hermana, amenazándola con revelarlos a su padre:

Detente;

no te apropincues a mí

que empañarás el candor

de mi castísimo bulto

y profanarás el culto

de las aras de mi honor;

porque mujer que fió

del caos de la sombra fría,

y en descrédito del día

nocturno amor aceptó,

no mirar consiga atento

mi semblante a voz profana,

pues víbora será humana

Anuario Calderoniano, 10, 2017, pp. 37-54. 
que con su, inficione, aliento.

$[\ldots]$

Pero yo minoraré

el escándalo que has hecho, diciendo al paterno pecho sacrilegios de tu fe.

(vv. 505-534)

Esta reacción, y la negativa de Beatriz a escuchar las disculpas de su hermana, determinan la cadena de burlas a las que sucesivamente la someterá Leonor para vengarse: primero, denunciándola al padre como destinataria de un billete amoroso que en realidad iba dirigido a ella; después, urdiendo el engaño por el que don Alonso, amigo de don Juan, deberá fingirse enamorado de su hermana para que ella también experimente el amor. Ni que decir tiene que Beatriz se enamora enseguida, y lo mismo don Alonso, que hasta ese momento había despreciado el amor noble por las aventuras ancilares y mercenarias, más sencillas y prácticas. Así, tanto Beatriz como don Alonso vuelven en el final a asumir unos papeles y un comportamiento conformes con su estatus sociodramático de nobles, desdiciéndose de la inversión que defendían al comienzo. El lenguaje en el que se expresa Beatriz puede interpretarse como una señalización de este movimiento de un rol invertido a un rol adecuado. Las exageraciones cultas que caracterizan su léxico y su sintaxis, y que imita don Alonso la primera vez que se dirige a ella, infringen las normas lingüísticas, exactamente como Beatriz y don Alonso, cada uno a su manera, infringen las normas sociales de comportamiento propias de la dama y del caballero $^{19}$. No será una casualidad, pues, el que Beatriz hable de forma oscura hasta el momento en que se da cuenta de que se está enamorando de don Alonso, es decir, al comienzo de la tercera jornada, cuando, como ha observado con acierto Arellano ${ }^{20}$, su estilo culto se evapora sin dejar rastro.

${ }^{19}$ Una interpretación parecida, aunque desde supuestos de crítica feminista, es la de Román, 1991, para quien el cultismo de Beatriz es una estrategia para evitar el matrimonio. Para otro tipo de lectura, que busca los referentes burlescos (esencialmente quevedianos) del cultismo exagerado de Beatriz, ver Barragán, 2013.

20 «Beatriz parece refugiarse en el culteranismo mientras no llega el amor. Significativamente la última queja de Beatriz, cuando increpa a quienes le han engañado, no tiene nada de pedante. Su lenguaje ha cambiado totalmente y no queda rastro de las ridiculeces anteriores...» (Arellano, 1981, p. 69). 
Pero volvamos a Con quien vengo, vengo. Aunque el comportamiento de Lisarda para con su hermana sea muy diferente del de la Beatriz de No hay burlas con el amor, ella también sufre un escarmiento cómico por la que al comienzo parece ser su impermeabilidad al amor. En su caso, el contrappasso consistirá en creer dos veces de haberse enamorado de un «imposible»: en un primer momento del que piensa ser el criado de don Juan, pero que en realidad es su amigo Octavio; en un segundo momento, del que supone ser don Juan, el amante de su hermana, pero que es el mismo Octavio. Otra de las penalidades que sufre Lisarda es que su hermano, don Sancho, la considera culpable de haber atentado al honor familiar mientras no tiene ninguna sospecha de Leonor, porque las apariencias conjuran en contra de Lisarda. Esta paradoja es exactamente la misma que encontramos en No hay burlas con el amor, y, con cierta inversión en el reparto de papeles, en El agua mansa. Lo único que diferencia Con quien vengo, vengo de estas dos comedias más tardías es que el equívoco en el que cae don Sancho acerca de la culpabilidad de Lisarda no se debe a un engaño deliberado de Leonor, sino a la casualidad de las circunstancias. El resultado, sin embargo, es análogo en las tres comedias: el personaje al que le toca el papel de guardián del honor se engaña o es engañado acerca del proceder de sus hijas o hermanas; esto determina una serie de equívocos que proyectan una duda cómica sobre su eficacia en la salvaguardia del honor familiar. En el caso de Con quien vengo, vengo el dramaturgo tiene buen cuidado de presentar al personaje del hermano, don Sancho, con unos rasgos que empañan su supuesta perfección noble en la práctica del honor. La historia de la traición que don Sancho ha cometido en daño de un amigo (que se revelará ser el propio Octavio), sustituyéndolo en una cita nocturna con su amada, ha corrido tanto que ha llegado a oídos de sus mismas hermanas. Cuando él las amenaza con algún «trágico escarmiento» (p. 1132a) si dan lugar a sospechas de honor, Lisarda le contesta afirmando que su comportamiento pasado le incapacita para darles a sus hermanas lecciones en este campo:

pues no aprendemos de ti

ni de tus celos, el ser

ni el lustre con que nacimos,

ni nos estuviera bien

el aprenderle de quien

viles hazañas oímos. 


$$
\begin{aligned}
& \text { Y así el valor y la fama } \\
& \text { de que al Cielo haces testigo } \\
& \text { guárdale para el amigo } \\
& \text { a quien quitaste la dama. }
\end{aligned}
$$

(p. 1132b)

Pero el rebajamiento cómico del rol de guardián del honor toca su ápice en El agua mansa, en la figura de don Toribio, el torpe y anticuado montañés que debería casarse con una de las dos hermanas, y está obsesionado por el honor de sus primas y posibles futuras esposas hasta extremos tan excesivos y ridículos, que el mismo padre de las damas declara en el final «que no tengo de dar dueño / tan bárbaro a una hija mía» (vv. 2905-2906). La vuelta de don Toribio a la Montaña, llevándose consigo en una «alforja al cuello» (v. 2901) la preciada joya de su ejecutoria de nobleza, remata de la forma más cómica posible la derrota de una forma anacrónica de entender el honor y la vida social en una ciudad como el Madrid de esos años ${ }^{21}$. El corolario de esta derrota, menos grotesco y más vivaz aunque no menos divertido, es el cambio repentino que experimenta doña Clara entre el final de la segunda jornada y el comienzo de la tercera. En la primera jornada, Clara extrañaba la tranquilidad del convento alcalaíno y le endilgaba a la más frívola Eugenia, impaciente por disfrutar los lujos y diversiones de Madrid, un largo sermón (vv. 520-559) sobre la fragilidad del honor de la mujer por casar. El punto de ruptura se da hacia finales de la segunda jornada, cuando Eugenia la acusa de no tener «filis», es decir, ingenio y atractivo, y la equipara por tanto al tonto don Toribio, al que ambas desprecian ${ }^{22}$. En parte Clara quiere demostrarle que sí tiene «filis» («que tener valor e ingenio / es tenerle y no decirle», vv. 1697-1698); en parte experimenta celos y un hondo despecho por creer que el galán que empieza a gustarle es el amante de su hermana: otra vez el temor que aquejaba a Lisarda en Con quien vengo, vengo, motivo que debemos reconocer como una forma de escarmiento cómico. Por todo ello, a partir de la tercera jornada Clara abandona por completo su papel paterno para asumir el

\footnotetext{
${ }^{21}$ Ver al respecto los acertados comentarios de García Santo-Tomás, 2004, p. 640.

22 «Eugenia: Obligarásme a decirte / lo que a mi primo. Clara: ¿Qué es? Eugenia: Que / tú tampoco tienes filis» (vv. 1482-1484).
} 
de dama enredadora: no ya víctima de la venganza de su hermana, como la Beatriz de No hay burlas con el amor, sino todo lo contrario ${ }^{23}$.

Queriendo resumir rápidamente la trayectoria dramática del tema de las hermanas rivales: en un comienzo (Con quien vengo, vengo) el tema solo sirve para poner en marcha la intriga, sin más desarrollo que el inicial; pero esta comedia ya conecta con el tema dos motivos dramáticos fundamentales que se desarrollarán mejor en No hay burlas con el amor: no solo la hermana reacia al amor se enamora de un «imposible», sino que las apariencias conjuran contra ella para que parezca la culpable de tener amores secretos. El agua mansa, aun reutilizando ambos motivos, insiste más en la diferencia y la rivalidad entre las dos hermanas, y mucho menos en el personaje del galán «al uso», pues la caracterización de don Félix es muy somera con respecto a la del don Alonso de No hay burlas con el amor. La novedad de El agua mansa en el tratamiento del tema es que Clara, la hermana recatada, urde una serie de trazas ingeniosas para atribuir a Eugenia culpas que no son suyas pero que parece sumamente verosímil que lo sean, jugando por tanto con la opinión negativa que todos tienen de Eugenia por su despejo y desenvoltura. Es verdad que este desarrollo del tema va anunciado por el título, que alude al conocido refrán y que se glosa al menos dos veces en el texto de la comedia ${ }^{24}$; pero esto no quita que Clara sea, entre todas las protagonistas de las comedias que hemos examinado, la más aguda, la más cínica, la que más deliberadamente se encarniza con su hermana, "porque tenga ella la pena / de la culpa que yo tengo» (vv. 2668-2669) como dice ya casi en el desenlace.

Dicho esto, y por más que a medida que nos alejamos de la primera comedia de esta serie podamos observar cierta intensificación del conflicto fraterno, hay que recordar que siempre las dos hermanas se casan con el galán del que están enamoradas, porque los asomos de rivalidad amorosa que pueden haber surgido en el desarrollo de la acción no llegan nunca a hacerse efectivos. Nunca, pues, llega Calderón a plantear

${ }^{23}$ Puede ser cierto, como afirma Campbell, 2003, p. 45, que Eugenia «representa las posibles degeneraciones de lo que en el siglo XVII era lo moderno: la moda, el coche, el galanteo mundano", frivolidades estas que no parecen interesar a Clara; pero en lo esencial, es decir, en el despejo y en la capacidad de manipular a los demás, sin ningún tipo de escrúpulos, Clara termina superando a su hermana menor y hasta dándole lecciones.

${ }^{24}$ Ver al respecto los comentarios de García Santo-Tomás, 2004, pp. 641-642, y Ontiveros, 2013, pp. 204-205. 
una situación de rivalidad encarnizada como la que dramatiza Lope de Vega en La dama boba. Repasemos rápidamente los elementos clave de esa intriga tan conocida. Laurencio, joven pobre, ama correspondido a la discreta y literata Nise, pero la deja porque decide que le conviene más casarse con su hermana boba, Finea, que dispone de una rica herencia. Laurencio convence por tanto a Liseo, el marido destinado a Finea por su padre, para que intercambie papeles con él y pretenda a Nise. Mientras, sus palabras de amor consiguen el milagro que los maestros no habían logrado: enamorada de Laurencio, Finea se transforma en discreta. Otavio, el padre de las dos jóvenes, termina burlado por la nueva ingeniosidad y astucia de Finea que esconde a Laurencio en el desván de la casa y se encuentra con él cuando todos creen que ella huye de los hombres. Nise se casa con Liseo pero más para vengarse de Laurencio que por otra cosa, afirmando «que en los agravios de amor / es la venganza gloriosa» (vv. 3037-3038).

La burla de los proyectos matrimoniales del padre y de su control sobre el comportamiento de las hijas es, en lo sustancial, análoga en $\mathrm{La}$ dama boba a lo que se observa en las comedias calderonianas que hemos examinado. Al contrario, las relaciones entre las dos hermanas son sin ninguna duda mucho más conflictivas: ambas están enamoradas de verdad del mismo galán, y luchan hasta casi el final por su amor, acudiendo para ello a todos los medios a su disposición (discusiones agrias, engaños y disimulaciones, denuncias al padre). Pero hay más. Se ha observado, como no podía ser menos, que en No hay burlas con el amor el padre de Beatriz, exasperado, le prohíbe los libros «de latín», pues «unas Horas en romance / le bastan a una mujer. / Bordar, labrar y coser / sepa solo; deje al hombre / el estudio» (vv. 1277-1281), del mismo modo que el padre de Nise en La dama boba se pregunta "¿Quién le mete a una mujer / con Petrarca y Garcilaso, / siendo su Virgilio y Taso / hilar, labrar y coser?» (vv. 2111-2114). Podríamos añadir que una queja parecida la pronuncia el padre de Eugenia en El agua mansa, cuando afirma que «lo menos que yo / en la corte he menester / es una hija discreta, / retórica ni poeta / y no de mal parecer» (vv. 1285-1288). Es cierto que ambas damas calderonianas, aunque de formas distintas, sufren un escarmiento de sus defectos, pero mucho menos grave del que sufre Nise en La dama boba: ya que experimentar el amor para quien siempre se había negado a este sentimiento, o verse superada en iniciativa y desenvoltura por la hermana mayor, no es lo mismo que padecer la pérdida del amor del 
galán, en favor de la hermana rival. En la comedia de Lope, de hecho, no podemos sustraernos a la impresión de que el dramaturgo simpatiza por Finea, que al final logra tenerlo todo, dinero, amor y discreción, mientras castiga a Nise por su «bachillería» con una decepción amorosa muy dura. Para completar el análisis comparado, hay que mencionar aunque muy de paso dos comedias más de Calderón, de capa y espada la una, palaciega la otra, que enlazan el tema de la bobería enfrentada a la discreción con el consabido esquema binario de la rivalidad entre dos primas, en ¿Cuál es mayor perfección, hermosura o discreción?, o dos hermanos, en De una causa dos efectos. Baste por ahora decir que en ambas comedias quien termina ganando, en el juego del amor, es el personaje que desde el comienzo se caracterizaba como discreto. Y es posible que la inversión, con respecto a lo que se observa en la lopesca Dama boba, no sea una casualidad, y que refleje preferencias e idiosincrasias de Calderón.

Para terminar, me gustaría resumir rápidamente los principales resultados de la indagación que he venido intentando en estas páginas: en las comedias cómicas que hemos examinado, las dinámicas que relacionan la instancia paterna con la instancia filial me parecen sustancialmente análogas a las que rigen la comedia cómica de la época de Lope; al contrario, con respecto a las comedias de Lope que tratan el tema de la rivalidad fraterna, las comedias de Calderón suavizan el conflicto y lo resuelven de forma más ligera, incluso - en el caso de las comedias protagonizadas por una pareja de hermanas - más satisfactoria para ambas damas. Al mismo tiempo, el esquema binario se utiliza como multiplicador de situaciones de intriga basadas en el paralelismo y el quiasmo, como generador de equívocos, como pretexto para agudas discusiones entre hermanas basadas en inversiones y retruécanos: en suma, como resorte cómico tras el que la rivalidad fraterna con sus tensiones reales acaba difuminándose hasta desaparecer por completo en el desenlace. 


\section{BibLIOGRAFÍA}

Antonucci, Fausta, "Prólogo», Pedro Calderón de la Barca, La dama duende, edición Fausta Antonucci, estudio preliminar Marc Vitse, Barcelona, Crítica (Biblioteca Clásica), 1999, pp. XXXI-LXXIII.

Antonucci, Fausta, "Sobre construcción y sentido de La dama duende de Calderón", Rivista di filologia e letterature ispaniche, 3, 2000, pp. 61-93.

Antonucci, Fausta, «Calderón y la madurez de la comedia áurea: La dama duende», Pedro Calderón de la Barca, La dama duende, edición Fausta Antonucci, Barcelona, Crítica (Clásicos y modernos), 2005, pp. 7-56.

AnTONucCi, Fausta, "Lo trágico y lo cómico mezclado”", en Norme per lo spettacolo / norme per lo spettatore. Teoria e prassi del teatro intorno all' "Arte nuevo" (Atti del Seminario internazionale), ed. Giulia Poggi y Maria Grazia Profeti, Firenze, Alinea, 2011, pp. 99-118.

Arellano, Ignacio, «Estudio» y «Apéndices», Pedro Calderón de la Barca, No hay burlas con el amor, ed. Ignacio Arellano, Pamplona, Ediciones de la Universidad de Navarra, 1981, pp. 13-151.

Arellano, Ignacio, «La generalización del agente cómico en la comedia de capa y espada», Criticón, 60, 1994, pp. 103-128.

Arellano, Ignacio, «La dama duende y sus notables casos», Cuadernos de teatro clásico, 15, 2001, pp. 127-140; ahora en El escenario cósmico. Estudios sobre la comedia de Calderón, Madrid / Frankfurt, Iberoamericana / Vervuert, 2006, pp. 187-201.

Arellano, Ignacio y Víctor García Ruiz, «Introducción» a Pedro Calderón de la Barca, El agua mansa / Guárdate del agua mansa, ed. de las dos versiones por Ignacio Arellano y Víctor García Ruiz, Kassel, Reichenberger, 1989, pp. 3-92.

Badía Herrera, Josefa, «Prólogo», Lope de Vega, El amigo hasta la muerte, ed. Josefa Badía Herrera, en Comedias. Parte XI, ed. Prolope, coord. Laura Fernández y Gonzalo Pontón, Madrid, Gredos, 2012, vol. II, pp. 3-22.

BARRAGÁn, Raquel, «Lo poético burlesco como recurso teatral en No hay burlas con el amon, Anuario calderoniano, 6, 2013, pp. 15-30.

Calderón de la Barca, Pedro, Con quien vengo, vengo, ed. ÁngelValbuena Briones, en Obras completas, I: Comedias, Madrid, Aguilar, 1987, pp. 1129-1165, $2^{\mathrm{a}}$ ed.

Calderón de la Barca, Pedro, El agua mansa / Guárdate del agua mansa, ed. de las dos versiones por Ignacio Arellano y Víctor García Ruiz, Kassel, Reichenberger, 1989.

Calderón de la Barca, Pedro, No hay burlas con el amor, edición de Ignacio Arellano, Colección Canon 60-TC/12. Disponible en línea: <http://tc12. uv.es/canon60/C6009_NoHayBurlasConElAmor.php> [21/07/2016].

Campbell, Ysla, "Aspectos ideológicos en Guárdate del agua mansa», en Teatro calderoniano sobre el tablado. Calderón y su puesta en escena a través de los siglos. 
XIII coloquio anglogermano sobre Calderón, ed. Manfred Tietz, Stuttgart, Franz Steiner Verlag, 2003, pp. 43-48.

Couderc, Christophe, Galanes y damas en la Comedia Nueva. Una lectura funcionalista del teatro español del Siglo de Oro, Madrid / Frankfurt, Iberoamericana /Vervuert, 2006.

García SAnto-Tomás, Enrique, "Calderón y las aguas revueltas de Guárdate del agua mansa», Arbor: Ciencia, pensamiento y cultura, 699-700, 2004, pp. 639-648.

GreER, Margaret R., "The (Self)Representation of Control in La dama duende», en The Golden Age Comedia. Text, Theory and Performance, ed. Charles Ganelin and Howard Mancing, West Lafayette, Purdue University Press, 1994, pp. 87-106.

Iglesias Feijoo, Luis, «"Que hay mujeres tramoyeras”: la "matemática perfecta” de la comedia calderoniana”, en La comedia de enredo. Actas de las XX Jornadas de teatro clásico, ed. Felipe B. Pedraza Jiménez y Rafael González Cañal, Almagro, Universidad de Castilla-La Mancha/Festival de Almagro, 1998, pp. 201-236.

JosA, Lola, El arte dramático de Juan Ruiz de Alarcón, Kassel, Reichenberger, 2002.

Morley, Sylvanus G. y Courtney Bruerton, Cronología de las comedias de Lope de Vega (1940), Madrid, Gredos, 1968.

Ontiveros, Adriana, "El agua mansa y la reescritura en la comedia de capa y espada de Calderón", Anuario Calderoniano, 6, 2013, pp. 199-210.

Osma, José María de, "Estudios sobre Calderón de la Barca. Notas a la comedia Con quien vengo, vengo», Hispania, 11, 3, 1928, pp. 221-226.

Pérez Magallón, Jesús, «Introducción», Pedro Calderón de la Barca, La dama duende, ed. Jesús Pérez Magallón, Madrid, Cátedra, 2011, pp. 11-95.

Román, David, «Spectacular Women: Sites of Gender Strife and Negotiation in Calderón's No hay burlas con el amor and on the Early Modern Spanish Stage», Theatre Journal, 43, 4, 1991, pp. 445-456.

Roncero, Victoriano, "Conflictos femeninos de poder: damas rivales en tres comedias de capa y espada de Calderón», Anuario calderoniano, 9, 2016, pp. 195-215.

SuÁrez Miramón, Ana, «Competencias entre hermanos en la tragedia calderoniana», Bulletin Hispanique, en prensa.

Trambaioli, Marcella, "El amigo hasta la muerte de Lope de Vega y El gallardo español de Miguel de Cervantes: entre intertextualidad y proyección autobiográfica", Arte Nuevo. Revista de estudios áureos, 1, 2014, pp. 106-133.

Vega, Lope de, La dama boba, edición de Marco Presotto, Colección Canon 60-TC/12. Disponible en línea: <http://tc12.uv.es/canon60/C6045_LaDamaBoba.php $>[21 / 07 / 2016]$.

VITSE, Marc, «El hecho literario», en Historia del teatro en España. 1 (Edad Media, Siglo XVI, Siglo XVII), ed. José María Díez Borque, Madrid, Taurus, 1983, pp. 507-612. 